\title{
An Unusual Case of Metastatic Non-Small Cell Lung Cancer Misidentified as Anaplastic Thyroid Cancer
}

\author{
Hye Mi Ko and Je-Ryong Kim \\ Department of Surgery and Research Institute for Medicinal Sciences, College of Medicine, Chungnam National University, Daejeon, \\ Korea
}

Metastases from other organs to the thyroid are considered to be extremely rare. Among thyroid malignancies, anaplastic thyroid cancer exhibits similar features to a number of other cancers and can therefore be easily misdiagnosed. In addition to the fine needle aspiration commonly used for assessing thyroid lesions, metastatic tumors and primary thyroid cancers can be distinguished through approaches such as immunohistochemistry, taking into consideration the possibility of other primary cancers. Here, we present a case of metastatic non-small cell lung cancer that was misidentified as anaplastic thyroid cancer and discuss its diagnosis and treatment.

Key Words: Thyroid cancer, Non-small cell lung carcinoma, Metastasis

\section{Introduction}

Metastases from other organs to the thyroid are extremely rare, with cases mainly observed in autopsies. ${ }^{1)}$ At autopsy, the breast and lung are the most common primary cancer sites that metastasize to the thyroid. ${ }^{2,3)}$

Anaplastic thyroid cancer, the most aggressive form of thyroid malignancies, exhibits a broad spectrum of morphological features and can be difficult to diagnose due to a high degree of reverse differentiation. Unlike papillary and follicular carcinomas, which have been well differentiated, anaplastic thyroid cancer shows rapid growth and a high local recurrence rate, with a 5 -year survival rate of $1.0-7.1 \%$. The average survival time is reported to be 4 to 12 months. ${ }^{4-6)}$

This report presents a case of thyroid anaplastic carcinoma diagnosed though fine needle aspiration
(FNA) in a 76-year-old patient previously diagnosed with non-small cell lung carcinoma (NSCLC).

\section{Case Report}

A 76-year-old woman with no respiratory symptoms or smoking history was admitted to the Department of Respiratory Medicine with a right lower lung mass found in chest PA detected on physical examination. Based on bronchoscopy performed for the evaluation of the lung mass, lung cancer was suspected and computed tomography (CT)-guided percutaneous core needle biopsy (PCNB) was performed. Positron emission tomography (PET)-CT imaging was performed before surgery to evaluate another metastasis (Fig. 1). The patient subsequently underwent a right lower lobectomy in the Department of Cardiothoracic Surgery, with the results of the post-

Received September 9, 2020 / Revised October 6, 2020 / Accepted October 6, 2020

Correspondence: Je-Ryong Kim, MD, PhD, Department of Surgery and Research Institute for Medicinal Sciences, College of Medicine, Chungnam National University, 33 Munwha-ro, Jung-gu, Daejeon 30530, Korea

Tel: 82-42-280-7175, Fax:82-42-257-8024, E-mail: kimjr@cnu.ac.kr

Copyright (c) the Korean Thyroid Association. All rights reserved.

(c) (1) This is an open-access article distributed under the terms of the Creative Commons Attribution Non-Commercial License (http://creative(1) (1) \& commons.org/licenses/by-nc/4.0/), which permits unrestricted non-commercial use, distribution, and reproduction in any medium, provided the original work is properly cited. 

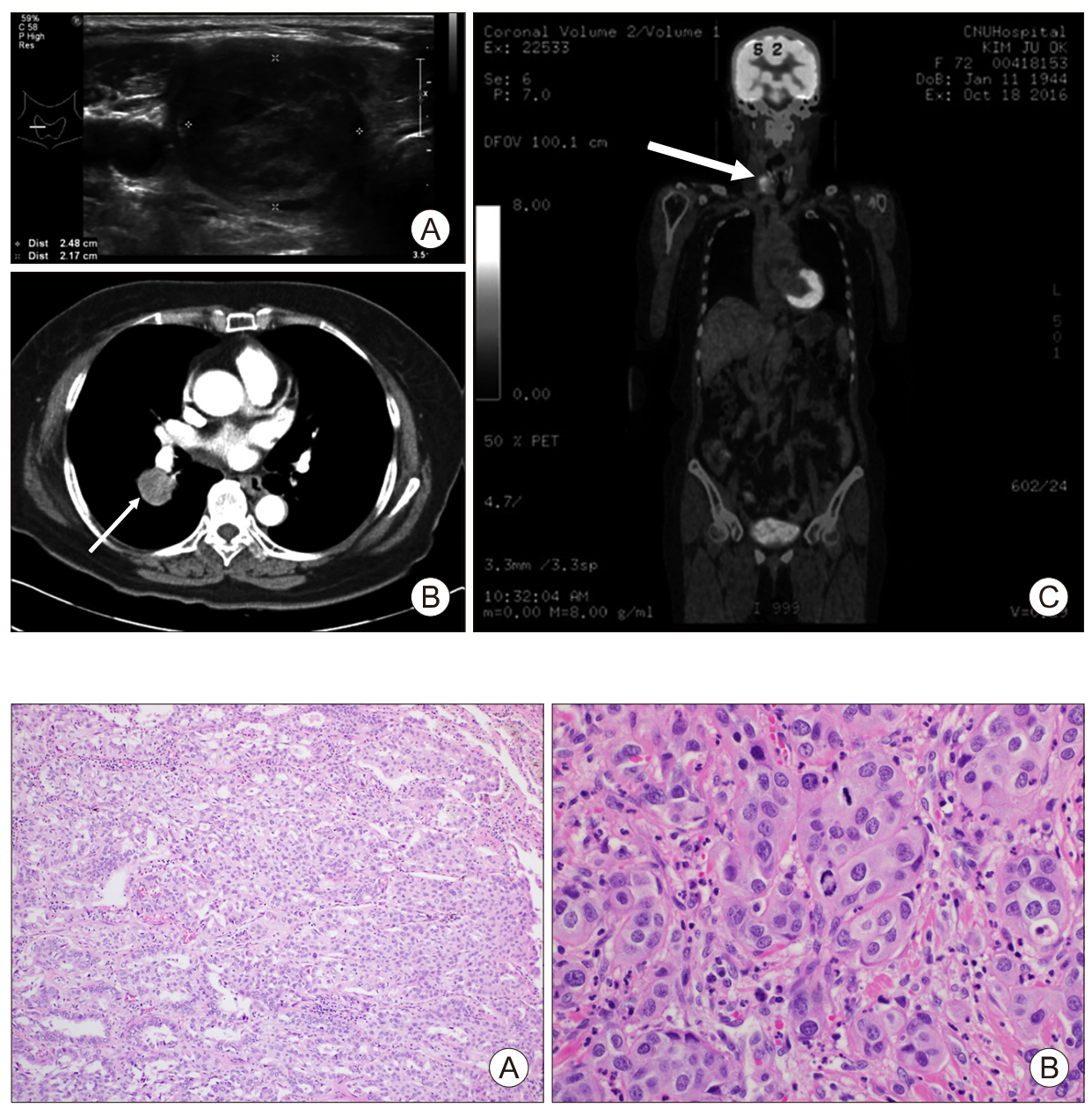

Fig. 1. (A) $2.48 \times 2.17 \mathrm{~cm}$ sized hypoechoic nodule at the right lobe was found on neck ultrasonogram after right lobectomy of lung. (B) Chest CT showed about 33 $\mathrm{mm}$ sized nodule (arrow) in right lower lobe with broad attachment in major fissure. (C) PET-CT showed increase uptake in right thyroid nodule (arrow) favor benign before thyroid surgery. operative histological examination indicating adenocarcinoma exhibiting acinar (40\%), papillary (30\%), and solid (30\%) patterns (Fig. 2A).

In addition to the management of NSCLC, the patient was followed by thyroid ultrasound of two benign thyroid nodules since 2016. During the postoperative follow-up after thoracic surgery, 4-years later, the patient was referred to Department of General Surgery for elevated carcinoembryonic antigen (CEA) and increased size of the right thyroid nodule. FNA of the thyroid nodule indicated anaplastic carcinoma. Total thyroidectomy with central neck dissection was performed. The results of the histopathological examination indicated metastatic adenocarcinoma of lung origin with poor differentiation, which is clinically a very rare occurrence (Fig. 2B). Blood tests performed before surgery showed the following findings: tumor marker CEA $39.59 \mathrm{ng} / \mathrm{mL}$, calcitonin $83 \mathrm{pg} / \mathrm{mL}$, free thyroxine $1.14 \mu \mathrm{g} / \mathrm{dL}$, free triiodothyronine $1.38 \mu \mathrm{g} / \mathrm{dL}$, thyroid-stimulating hormone (TSH) $0.98 \mu \mathrm{lU} / \mathrm{mL}$, anti-thyroglobulin antibodies $9.56 \mathrm{U} / \mathrm{mL}$, parathyroid hormone $36.81 \mathrm{ng} / \mathrm{L}$, and thyroglobulin $31.09 \mu \mathrm{g} / \mathrm{L}$. No distinguishing biochemical features generally observed in anaplastic thyroid cancer were detected, such as the lack of thyroglobulin production, the inability to carry iodine, or the lack of TSH receptors.

The patient was subsequently seen in the Department of Respiratory Medicine for treatment of the cancer of pulmonary origin. The thyroid tissue was tested for epidermal growth factor receptor (EGFR) mutations, anaplastic lymphoma kinase (ALK), and programmed death-ligand 1 (PD- L1) in the primary lung tissue (Table 1). PET-CT imaging performed after thyroid surgery detected multiple lymph node metastases, with hypermetabolism in right level IIB, III, IV, and VI border zone lymph nodes. However, no significant lymphadenopathy was observed on neck CT performed before thyroid surgery, as mentioned 
Metastatic NSCLC Misidentified as Thyroid Cancer

Table 1. Immunohistochemical staining results from postoperative biopsy

\begin{tabular}{lcccc} 
& EGFR & ALK & PD-L1 & BRAF \\
\hline Lung & Exon21 L858R mutant & Negative & $\begin{array}{c}\text { Tumor proportion score; } \\
\text { Thy -low expression }\end{array}$ & - \\
Thyid & Exon21 L858R mutant & - & - & Wild type \\
\hline
\end{tabular}

ALK: anaplastic lymphoma kinase, BRAF: B-type Raf kinase gene, EGFR: epidermal growth factor receptor, PD-L1: programmed death-ligand 1

earlier. Brain MRI showed no metastatic lesions or specific findings, and chest CT detected no abnormalities in either of the neck lymph nodes.

Based on the mutations detected through additional genetic testing performed following total thyroidectomy, we initiated treatment for NSCLC recurrence using gefitnib (an EGFR inhibitor) based on Exon21 L858R mutation.

\section{Discussion}

Despite the rich vascular supply to the gland, metastases to the thyroid are extremely rare, ${ }^{7)}$ accounting for less than $4 \%$ of all malignant thyroid tumors. ${ }^{1,8)}$

Anaplastic thyroid cancer is a highly malignant disease. Due to its aggressive nature (which distinguishes it from other thyroid cancers), it is unlikely to be misdiagnosed as another disease. A cancer that has metastasized to the thyroid gland may be difficult to distinguish histologically from an undifferentiated cancer. This can be the case in situations in which the cancer transferred to the neck exhibits dedifferentiation, as in the reported case.

According to the National Comprehensive Cancer Network (NCCN) guidelines, lung cancer is classified into "small cell lung cancer" (15\%) and NSCLC (85\%) according to the histological features. NSCLC is further subclassified into adenocarcinoma (40\% of NSCLC cases), squamous cell carcinoma (30\%), or large cell carcinoma. Differentiation between squamous cells and the non-squamous epithelium has important connotations for the treatment of NSCLC. In many cases of non-squamous cell carcinoma, including adenocarcinoma, an induced mutation (driver mutation) is observed in EGFR, ALK, ROS1, or BRAF genes. It is important to test for these mutations, particularly
EGFR and ALK, in all cases. When such mutations are found, drug treatment appropriate for the specific mutation should be selected. If mutations are not present, the PD-L1 test should be performed to determine whether single agent immunotherapy, combination immunotherapy, or a combination of immunotherapy with chemotherapy should be implemented, depending on the degree of expression.

Adenocarcinoma is the most common histological type found in patients with lung cancer, which has metastasized to the thyroid, with histological types associated with different life expectancies. While mutations in the EGFR and EML4-ALK genes are associated with thyroid metastases, the exact mechanism underlying this interaction has not yet been elucidated.

\section{Diagnosis}

Thyroid cancers can be qualitatively diagnosed through FNA and immunohistochemistry. FNA is a fast, minimally invasive, and affordable technique that can be used to differentiate between metastatic lung cancer and thyroid cancer. Patients with thyroid nodules should consider an FNA to rule out other disorders. However, in some cases, FNA alone is not sufficient, and it may be difficult to distinguish between undifferentiated thyroid cancer and metastatic malignant tumor. ${ }^{3,9,10)}$

Immunohistochemistry exhibits a high accuracy in diagnosing thyroid cancer, with the reported false negative rate of less than $1 \%$ and the false positive rate of approximately $2-3 \%{ }^{11,12)}$ Additionally, immunohistochemistry can be used to distinguish between metastases and primary thyroid tumors. ${ }^{13)}$ On immunohistochemistry examination, undifferentiated thyroid cancer is generally negative for thyroid globulin and calcitonin. Approximately half and one-third of 
cases are positive for pan-keratin and epithelial membrane antigen, respectively, while vimentin is found in $90 \%$ of cases. Thyroid transcription factor-1 is present in $0-50 \%$ of the cases. These markers can distinguish anaplastic thyroid cancer from other diseases with similar presentation (Table 2, Fig. 3).

Among findings of imaging modalities such as

Table 2. Immunohistochemical staining results from thyroid

\begin{tabular}{lc}
\hline Thyroglobulin & - \\
TTF-1 & + \\
Anti BRAF V600E & - \\
Galectin-3 & + \\
Vimentin & + \\
Beta catenin &,- membranous \\
CD31 & - \\
p53 & + \\
Ki-67 index & $70 \%$ \\
\hline
\end{tabular}

BRAF: B-type Raf kinase gene, TTF-1: thyroid transcription factor-1
PET-CT, detection of a "cold" nodule on thyroid scan, a hyperechoic mass on ultrasound, and calcification of the thyroid parenchyma and nodules can be seen as features of thyroid metastases. ${ }^{12,14)}$

Biologically, thyroid hormone balance is unaffected by metastatic thyroid nodules. ${ }^{15)}$ The thyroid hormone levels were found to be normal in the presented case.

\section{Surgical Treatment}

In the case of metastatic cancer of the thyroid, surgery is performed to address the potential morbidity related to tumor recurrence in the neck. However, the prognosis remains poor in most cases, and the surgery does not contribute to prolonging the life of patients. ${ }^{16,17)}$

For metastatic cancer, systemic treatment with chemotherapy or targeted therapy is the standard treatment. Radioiodine treatment is not indicated for thyroid metastases. A case report describing a patient
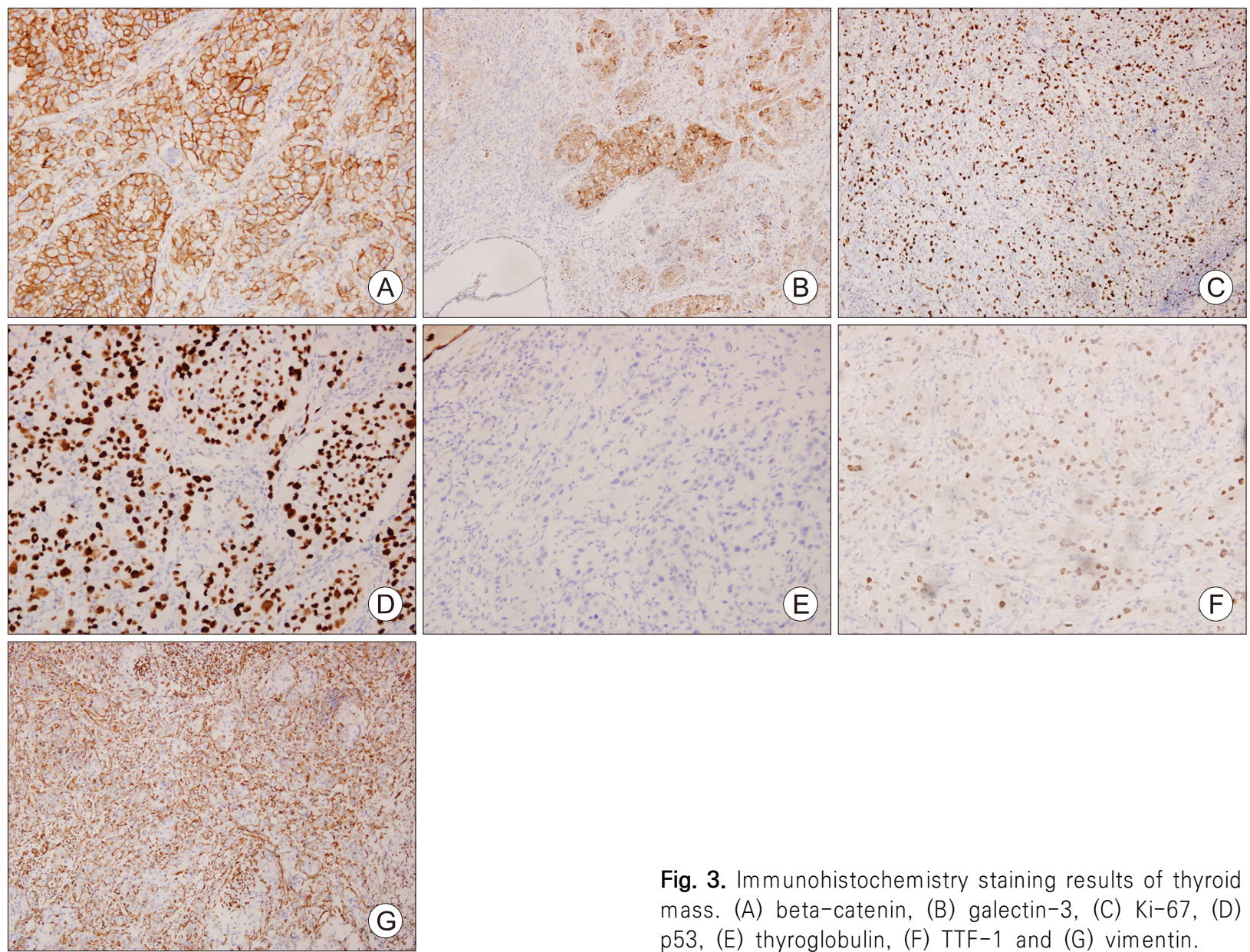

(F)

Fig. 3. Immunohistochemistry staining results of thyroid mass. (A) beta-catenin, (B) galectin-3, (C) Ki-67, (D) p53, (E) thyroglobulin, (F) TTF-1 and (G) vimentin. 
with thyroid metastases from lung cancer with an EGFR mutation reported a marked response of the thyroid and lung masses after the patient was treated with erlotinib. ${ }^{18)}$ Radiation therapy was described as an alternative approach for partial symptom relief in thyroid cancer. ${ }^{19)}$

We present a rare case of a patient with metastases to the thyroid gland following diagnosis of NSCLC. In this case, thyroidectomy did not appear to affect the patient's disease progression, and neck lymph node metastases were detected immediately after thyroid surgery. Therefore, active systemic therapy for primary cancer is expected to affect the disease progression in patients.

Metastasis from the lungs to the thyroid is rare and may be confused with primary thyroid cancer if it does not clearly display the clinical features described above, making it difficult to accurately diagnose. Therefore, a close follow-up and diagnostic examination of thyroid nodules are required.

\section{Conflicts of Interest}

No potential conflict of interest relevant to this article was reported.

\section{Orcid}

Hye Mi Ko: https://orcid.org/0000-0002-6621-8761

Je-Ryong Kim: https://orcid.org/0000-0002-3712-6083

\section{References}

1) Lam KY, Lo CY. Metastatic tumors of the thyroid gland: a study of 79 cases in Chinese patients. Arch Pathol Lab Med 1998;122(1):37-41.

2) Mirallie E, Rigaud J, Mathonnet M, Gibelin H, Regenet N, Hamy A, et al. Management and prognosis of metastases to the thyroid gland. J Am Coll Surg 2005;200(2):203-7.

3) Kim TY, Kim WB, Gong G, Hong SJ, Shong YK. Metastasis to the thyroid diagnosed by fine-needle aspiration biopsy. Clin Endocrinol (Oxf) 2005;62(2):236-41.

4) Nel CJ, van Heerden JA, Goellner JR, Gharib H, McConahey
WM, Taylor WF, et al. Anaplastic carcinoma of the thyroid: a clinicopathologic study of 82 cases. Mayo Clin Proc 1985;60(1):51-8.

5) Venkatesh YS, Ordonez NG, Schultz PN, Hickey RC, Goepfert H, Samaan NA. Anaplastic carcinoma of the thyroid. A clinicopathologic study of 121 cases. Cancer 1990;66(2): 321-30.

6) Demeter JG, De Jong SA, Lawrence AM, Paloyan E. Anaplastic thyroid carcinoma: risk factors and outcome. Surgery 1991;110(6):956-61; discussion 61-3.

7) Katsenos S, Archondakis S, Vaias M, Skoulikaris N. Thyroid gland metastasis from small cell lung cancer: an unusual site of metastatic spread. J Thorac Dis 2013;5(2):E21-4.

8) Rosen IB, Walfish PG, Bain J, Bedard YC. Secondary malignancy of the thyroid gland and its management. Ann Surg Oncol 1995;2(3):252-6.

9) Brown RS, Mawdsley S, Duchesne GM. Death due to thyroid metastases from renal cell carcinoma. Clin Oncol ( $R$ Coll Radiol) 1998;10(4):267-9.

10) Cilengir AH, Kalayci TO, Duygulu G, Rezanko TA, Inci MF. Metastasis of renal clear cell carcinoma to thyroid gland mimicking adenomatous goiter. Pol J Radiol 2016;81:618-21.

11) Yamazaki $H$, Iwasaki $H$, Yamashita $T$, Yoshida $T$, Suganuma $\mathrm{N}$, Yamanaka $\mathrm{T}$, et al. A case of pneumothorax after treatment with lenvatinib for anaplastic thyroid cancer with lung metastasis. Case Rep Endocrinol 2018;2018:7875929.

12) Corrias A, Einaudi S, Chiorboli E, Weber G, Crino A, Andreo $\mathrm{M}$, et al. Accuracy of fine needle aspiration biopsy of thyroid nodules in detecting malignancy in childhood: comparison with conventional clinical, laboratory, and imaging approaches. J Clin Endocrinol Metab 2001;86(10):4644-8.

13) Dao A, Jabir H, Taleb A, Benchakroun N, Bouchbika Z, Nezha T, et al. Lung adenocarcinoma with thyroid metastasis: a case report. BMC Res Notes 2017;10(1):130.

14) Wey SL, Chang KM. Tumor-to-tumor metastasis: lung carcinoma metastasizing to thyroid neoplasms. Case Rep Pathol 2015;2015:153932.

15) Bakhos D, Lescanne E, Beutter P, Moriniere S. Metastasis of renal carcinoma to the thyroid gland. Ann Otolaryngol Chir Cervicofac 2007;124(6):301-4.

16) Papi G, Fadda G, Corsello SM, Corrado S, Rossi ED, Radighieri E, et al. Metastases to the thyroid gland: prevalence, clinicopathological aspects and prognosis: a 10-year experience. Clin Endocrinol (Oxf) 2007;66(4):565-71.

17) Dequanter D, Lothaire P, Larsimont D, de Saint-Aubain de Somerhausen N, Andry G. Intrathyroid metastasis: 11 cases. Ann Endocrinol (Paris) 2004;65(3):205-8.

18) Albany C, Jain A, Ulbright TM, Einhorn LH. Lung cancer, thyroid cancer or both: an unusual case presentation. J Thorac Dis 2011;3(4):271-3.

19) Wood K, Vini L, Harmer C. Metastases to the thyroid gland: the Royal Marsden experience. Eur J Surg Oncol 2004;30(6): 583-8. 